\title{
ON ALZER'S INEQUALITY AND ITS GENERALIZED FORMS
}

\author{
JIDING LIAO AND KAIZHONG GUAN
}

Abstract. By using the theory of multiplicatively convex functions, we present some general forms of Alzer's inequality. As consequence, some relevant results in the literature are recovered and an open problem by J. S. Ume [12] is also solved.

Mathematics subject classification (2010): 26A51, 26D15.

Keywords and phrases: Multiplicative convexity, Alzer's inequality, generalization.

\section{REFERENCES}

[1] H. Alzer, On an inequality of Minc and Sathre, J. Math. Anal. Appl., 179 (1993), 396-402.

[2] J. SÁNDOR, On an inequality of Alzer, J. Math. Anal. Appl., 192 (1995), 1034-1035.

[3] J. S. UME, An elementary proof of H. Alzer's inequality, Math. Japonica, 44 (1996), 521-522.

[4] J.-CH. KuANG, Some extensions and refinements of Minc-Sathre's inequality, Math. Gaz., 83 (1999), $123-127$.

[5] F. QI, Generalization of H. Alzer's inequality, J. Math. Anal. Appl., 240 (1999), $294-297$.

[6] F. QI AND L. Debnath, On a new generalization of Alzer's inequality, Internat. J. Math. Math. Sci., 23, 12 (2000), 815-818.

[7] Z. XU AND D. XU, A general form of Alzer's inequality, Comput. Math. Appl., 44, 3-4 (2002), 365373.

[8] G. Bennetr, Meaningful sequences, Houston J. Math., 33, 2 (2007), 555-580.

[9] N. ElezoviĆ And J. PeČArić, On Alzer's inequality, J. Math. Anal. Appl., 223 (1998), 366-369.

[10] C. P. Niculescu, Convexity according to the geometric mean, Math. Inequal. Appl., 2 (2000), 155167.

[11] C. P. Niculescu And L. E. Persson, Convex Functions and Their Applications-A Contemporary Approach, Springer-Verlag, New York, 2006.

[12] J. S. UME, An inequality for a positive real function, Math. Inequl. Appl., 4 (2002), 693-696.

[13] F. QI, B.-N. GuO, Monotonicity of sequences involving convex function and sequence, Math. Inequ. Appl., 2 (2006), 247-254. 